\title{
Qualidade microbiológica do leite cru produzido no Norte de Minas Gerais*
}

\section{Microbiological quality of raw milk produced in northern of Minas Gerais}

\author{
Isabela Rocha Menezes, ${ }^{* *}$ Anna Christina de Almeida, ${ }^{* *}$ Rodrigo Pereira Morão, ${ }^{* *}$ Soraya Vanely Reis, ${ }^{* *}$ \\ Claudinei Alves dos Santos, ${ }^{* *}$ Isabella Luiza N. Lopes ${ }^{* *}$
}

\begin{abstract}
Resumo
Objetivou-se verificar a contaminação do leite cru por micro-organismos mesófilos, psicrotróficos, coliformes a $45^{\circ} \mathrm{C}$ e Enterococcus spp., produzido por rebanhos mestiços, em 30 unidades agrícolas familiares produtoras de leite em Juramento e Montes Claros, na região Norte de Minas gerais. Houve quatro coletas de amostras durante um ano, sendo duas na época de chuva e duas na época da seca. Coletaram-se amostras de leite cru e cru refrigerado, observando-se a contagem total de micro-organismos mesófilos, psicrotróficos, Enterococcus spp. e a contagem de coliformes a $45^{\circ} \mathrm{C}$. Coletaram-se também, amostras de Swabs de equipamentos utilizados em ordenha (baldes e latões) utilizando-se a técnica do esfregaço em superfície, a fim de avaliar a contagem total bacteriana presente nesses utensílios para verificar a sua higienização. As amostras de leite apresentaram contaminação elevada por micro-organismos aeróbios mesófilos, psicrotróficos, Enterococcus spp., coliformes a $45^{\circ} \mathrm{C}$, comprometendo a qualidade higiênico-sanitária do produto, bem como as amostras de Swabs, que apresentaram níveis de contaminação elevados, quanto à presença de aeróbios mesófilos. Existiu deficiência quanto às práticas de antissepsias adotadas nos equipamentos utilizados na ordenha, levando a contaminações acima do permitido por mesófilos aeróbios, tornando-se evidente a necessidade de adoção de boas práticas agropecuárias e maiores investimentos em treinamentos e assistência técnica de qualidade com o intuito de provocar melhorias na qualidade microbiológica do leite produzido nessa região.
\end{abstract}

Palavras-chave: coliformes, Enterococcus spp., mesófilos.

\begin{abstract}
This study aimed to investigate the contaminationby mesophilic, psychrotrophic, coliform microorganisms at $45^{\circ} \mathrm{C}$ and Enterococcus spp., produced by crossbred herds, in raw milk produced in 30 family dairy farms in Juramento and Montes Claros, Northern Minas Gerais. Samples were collected 4 times, 2 during the rainy season and 2 during the dry season. Raw milk samples and milk samples refrigerated were collected, observing the total count of mesophilic, psychrotrophic microorganisms, Enterococcus sppand coliform at $45^{\circ} \mathrm{C}$. Was collected too, Swabs samples from milking materials (buckets, cans) were collected using the surface scrubbing technique, in order to assess the total bacterial count of those utensils to verify their hygiene. The milk samples showed high contamination by micro-organisms aerobic mesophilic, psychrotrophic, Enterococcus spp., Coliforms at $45^{\circ} \mathrm{C}$, compromising the sanitary quality of the product as well as Swab samples that hight contamination levels, with aerobic mesophilic. What compromised the sanitary quality of the product. There are shortcomings regarding antiseptic practices adopted on the milking equipment, leading to aerobic mesophilic contamination higher than allowed. Becoming evident the need for adoption of good agricultural practices, greater investments in training and quality technical assistance in order to stimulate improvements in the microbiological quality of the milk produced in the region.
\end{abstract}

Keywords: coliforms, Enterococcus spp, Mesophilic.

\section{Introdução}

O Brasil se insere na quinta posição do ranking mundial de produção de leite (IBGE, 2014), e é característico por possuir produtores de leite de excelente qualidade e que atendam às exigências do mercado internacional, porém é notoriamente conhecido por ainda possuir regiões com produção de qualidade não satisfatória (Ribas et al., 2004). As características da baixa qualidade na produção leiteira no Brasil são os principais fatores que impedem o desenvolvimento mais acelerado dessa, e como consequência resulta em produtos beneficiados de qualidade insatisfatória (Nero et al., 2004; Nero et al., 2005; Arcuri et al., 2006; Rocha et al., 2006). Em geral, o Brasil perde em competitividade no mercado mundial por apresentar deficiência produtiva e de qualidade da matéria-prima, pois o leite innatura apresenta altas contagens de micro-organismos deterioradores (VALLIN et al., 2009).

Existem diversos micro-organismos contaminantes do leite e prejudiciais à sua qualidade, tais como os mesófilos, psicrotróficos, termotolerantes e micro-organismos Enterococcus spp. (ARCURI et al., 2006; SANTOS eFONSECA, 2007; TEBALDI et al., 2008). Sendo estes micro-organismosoriginados principalmente, do ambiente de ordenha e utensílios empregados, além dos próprios animais (YAMAZI et al., 2010).

\footnotetext{
*Recebido em 24 de abril de 2014 e aceito em 26 de março de 2015.

**Universidade Federal de Minas Gerais. Campus Montes Claros. Av. Universitária, 1000. Montes Claros, MG. 38904-006

Autor para correspondência. E-mail: annachristinadealmeida@gmail.com.
} 
A existência de problemas relacionados às condições higiênicas deficientes durante os processos de obtenção, manipulação e conservação, vem sendo considerada como uma das principais razões para a perda de sua qualidade. Medidas com intuito de melhorar a qualidade do leite vêm sendo implantadas deste o ano de 2002 com a publicação Instrução Normativa Instrução Normativa N51(BRASIL, 2002). Porém, os produtores em escalas menores de produção, conforme observado na região Norte de Minas Gerais e em outras do país, demonstraram dificuldades em adequar o leite cru aos padrões estabelecidos por essa legislação, sendo necessárias alterações previstas na Instrução Normativa $\mathrm{N}^{\circ} 62$ (BRASIL, 2011), que estabeleceu novos padrões para contaminação microbiana do leite e Contagem de Células Somáticas, visando melhoras graduais na qualidade do leite.

Dessa forma, pretendeu-se, com este estudo, verificar a qualidade microbiológica do leite cru produzido por rebanhos mestiços de unidades agrícolas familiares produtoras de leite no Norte de Minas Gerais, e a sua adequação a legislação vigente quanto à qualidade microbiológica.

\section{Material e métodos}

Obtiveram-se amostras de leite cru em 30 unidades agrícolas familiares produtoras de leite, localizadas nos municípios de Juramento e Montes Claros, Norte do Estado de Minas Gerais. Foram quatro coletas durante um ano, sendo duas na época de chuva (dezembro/2010 e outubro/2011) e duas na época da seca (março/2011 e junho/2011).

No total de todas as quatro coletas, foram retiradas 240 amostras, ou seja, 60 amostras por época de coleta, sendo que de cada propriedade retiraram-se, com coletores de aço inoxidável, dois pool de $200 \mathrm{~mL}$ do leite acondicionado nos latões ou dos tanques de refrigeração, que eram armazenados em frascos estéreis. As amostras eram transportadas em caixas térmicas sob refrigeração e eram encaminhadas ao Laboratório de Microbiologia Aplicada do Instituto de Ciências Agrárias da Universidade Federal de Minas Gerais. Das duas amostras coletadas em cada propriedade e em cada época, uma era denominada de leite cru e a outra de leite cru refrigerado. Sendo a primeira imediatamente congelada para posteriores analises, e a segunda passava por refrigeração por um período de 48 horas a $7^{\circ} \mathrm{C}$, antes de ser analisada. Com as amostras coletadas, objetivou-se verificar a contagem total de micro-organismos mesófilos, psicrotróficos, Enterococcus spp. e a contagem de coliformes a $45^{\circ} \mathrm{C}$.

Coletaram-se também, 120 amostras de Swabs pela técnica de arraste em superfície (APHA, 2001) de equipamentos utilizados em ordenha para se avaliar a contagem total bacteriana (CBT) presente nesses utensílios, com o objetivo de verificar a eficiência das práticas de higienização adotadas nas propriedades.

Para análise do conteúdo microbiológico do leite e dos equipamentos de ordenha, utilizou-se a metodologia descrita por APHA (2001) para determinar a Contagem Total de Mesófilos (UFC. $\mathrm{mL}^{-1}$ ), de Psicrotróficos (UFC. $\mathrm{mL}^{-1}$ ), de Enterococcus spp. (UFC. $\mathrm{mL}^{-1}$ ), de Aeróbios Mesófilos em superfície (UFC. $\mathrm{cm}^{2}$ ) e Contagem de Coliformes a $45^{\circ} \mathrm{C}$ pela técnica do Número Mais Provável, expresso em Número Mais Provável por mililitro (NMP. $\mathrm{mL}^{-1}$ ).
Foi utilizado o procedimento ProcMeans do programa estatístico StatisticalAnalysis System (SAS, 2012), para realizar uma estatística descritiva para avaliar os resultados encontrados. E para avaliar a influencia da época na contagem dos micro-organismos Mesófilos, Psicotróficos e Enterococcus sp., foi realizado o Teste $\mathrm{T}$ de Student., por meio do pacote ProcUnivariate (SAS, 2012), a um nível de significância de 5\%.

Utilizou-se o procedimento Procfreq do programa estatístico StatisticalAnalysis System(SAS, 2012) determinando-se a frequência de amostras de leite cru e cru refrigerado fora dos limites estabelecidos pela legislação vigente nos anos em que foram realizadas as coletas (BRASIL, 2002) e a legislação vigente atualmente (BRASIL, 2011), e que estão descritos na Tabela 1.

Tabela 1: Classes para contagem bacteriana total (CBT) de microorganismos aeróbios mesófilos no leite

\begin{tabular}{|c|c|}
\hline lasses & Aceitável \\
\hline imite 1- estabelecido pela IN. 51 & CBT inferior ou igual a $7,5 \times 10^{4}$ UFC. $\mathrm{mL}^{-1}$ \\
\hline $\begin{array}{l}\text { imite 2- IN. } 51 \text { previa para ser } \\
\text { alcançado em julho de } 2011\end{array}$ & CBT inferior ou igual $4 \times 10^{5} \mathrm{UFC} . \mathrm{mL}^{-1}$ \\
\hline $\begin{array}{l}\text { imite 3- estabelecido pela IN. } 62 \\
\text { em dezembro de } 2011\end{array}$ & $\begin{array}{l}\text { Inferior ou igual a } 3 \times 10^{5} \mathrm{UFC} \cdot \mathrm{mL}^{-1} \text { para as } \\
\text { regiões Sul, Sudeste e Centro-Oeste. }\end{array}$ \\
\hline
\end{tabular}

Para avaliação da conformidade nos níveis de contaminação por psicrotróficos utilizaram-se limites recomendados por Sørhaug\&Stepaniak (1997) e Pinto et al. (2006), os quais consideraram contagens de até $5 \times 10^{5}$ UFC. $\mathrm{mL}^{1}$, valor que, segundo esses autores, não são suficientes para promover alterações significativas em derivados. E para Enterococcus spp. foi avaliado verificando-se a frequência de amostras com valores menor ou igual a $10^{3} \mathrm{UFC} \cdot \mathrm{mL}^{-1}$, conforme recomendados por Holm et al. (2004).

No método laboratorial que avalia a Contagem de coliformes a $45^{\circ} \mathrm{C}$ considerou-se como classe aceitável quando coliformes a $45^{\circ} \mathrm{C}$ fossem menores ou igual a 0,03 Número Mais Provável/ $\mathrm{mL}$ (NMP. $\mathrm{mL}^{-1}$ ); classe não aceitável com coliformes a $45^{\circ} \mathrm{C}$ maior ou igual a $0,03 \mathrm{NMP} \cdot \mathrm{mL}^{-1}$, visto que a legislação vigente não determina valores limites para leite cru, porém, com objetivo de definir um limite para avaliação dos dados, optou-se por adotar os mesmos valores definidos para leite pasteurizado (BRASIL, 2011).

\section{Resultados}

As médias gerais, independentes da época de estudo para as contagens de Aeróbios Mesófilos, Coliformes à $45^{\circ} \mathrm{C}$ e de Psicrotróficos e Enterococcus spp., no leite cru foram respectivamente de $44,9 \times 10^{6}$ UFC.mL-1 $; 0,25 \times 10^{-2} \mathrm{NMP}_{\mathrm{mL}}{ }^{-1} ; 16,1$ $\mathrm{x} 10^{6} \mathrm{UFC} \cdot \mathrm{mL}^{-1}$ e $1,8 \times 10^{6} \mathrm{UFC} \cdot \mathrm{mL}^{-1}$. Para o leite cru refrigerado foi de $35,5 \times 10^{6}$ UFC. $\mathrm{mL}^{-1} ; 3 \mathrm{NMP} . \mathrm{mL}^{-1} ; 26,4 \times 10^{6}$ UFC. $\mathrm{mL}^{-1} \mathrm{e}$ $19,9 \times 10^{6} \mathrm{UFC} \cdot \mathrm{mL}^{-1}$, respectivamente.

Observaram-se médias de contaminação por micro-organismos mesófilos do leite cru sem refrigeração e refrigerado consideradas maiores, quando comparadas com as recomendações da IN. 62 (BRASIL, 2011) que é de $3 \times 10^{5} \mathrm{UFC} . \mathrm{mL}^{-1}$ por rebanho. Vários fatores podem ter contribuído para elevar esses valores, como 
a não adoção de práticas higiênicas adequadas no momento da ordenha e nos utensílios utilizados nesta (NERO et al., 2005). Sendo que o leite é considerado, por AYARAO e WOLFGANG (2003), de qualidade microbiológica pobre quando apresenta UFC. $\mathrm{mL}^{-1}$ acima de $1 \times 10^{4}$.

Quanto à influência da época sobre a contagem de aeróbios mesófilos, psicrotróficos e Enterococcusspp, nas amostras de leite, os dados estão apresentados na Tabela 2.

Tabela 2: Influência da época na contaminação por micro-organismos mesófilos,em leite cru e cru refrigerado produzido por unidades agrícolas familiares produtoras de leite no norte de Minas Gerais

\begin{tabular}{c|ccc}
\hline Micro-organismos & Épocas & Leite cru & Leite cru refrigerado \\
\hline Mesófilos & Chuva & $4,8 \times 10^{7 \mathrm{~ns}}$ & $3,2 \times 10^{7 \mathrm{~ns}}$ \\
\cline { 2 - 3 }$\left(\right.$ UFC. $\left.\mathrm{mL}^{-1}\right)$ & Seca & $4,1 \times 10^{7 \mathrm{~ns}}$ & $3,9 \times 10^{7 \mathrm{~ns}}$ \\
\hline Psicrotróficos & Chuva & $2,3 \times 10^{7 \mathrm{~ns}}$ & $1,83 \times 10^{7 \mathrm{~ns}}$ \\
\cline { 2 - 3 }$\left(\right.$ UFC. $\left.\mathrm{mL}^{-1}\right)$ & Seca & $9,33 \times 10^{6 \mathrm{~ns}}$ & $3,53 \times 10^{7 \mathrm{~ns}}$ \\
\hline Enterococcus spp. & Chuva & $2,9 \times 10^{4 \mathrm{~ns}}$ & $2,9 \times 10^{7^{*}}$ \\
\cline { 2 - 4 }$\left(\right.$ UFC. $\left.\mathrm{mL}^{-1}\right)$ & Seca & $3,7 \times 10^{6 \mathrm{~ns}}$ & $1,1 \times 10^{7}$ \\
\hline
\end{tabular}

Nota: ${ }^{\text {ns }}=$ não significativo ao nível de significância de $5 \%$ e "= apresentou diferença estatística ao nível de significância de $5 \%$, pelo Teste T de Student, nas colunas.

Apesar das amostras de leite cru sem refrigeração e cru refrigerado não apresentarem diferença significativa de microorganismos mesófilos e psicrotróficos à $5 \%$ de significância pelo Teste $\mathrm{T}$ de Student, entre as épocas avaliadas, observouse (Tabela 3) no período de chuvas quanto a de secas, uma pequena porcentagem de amostras de leite cru e leite cru refrigerado dentro dos limites estabelecidos pelas legislações (Tabela 1). Havendo, portanto uma frequência mais considerável de amostras que não atendem aos limites estabelecidos atualamente pela IN.62 (limite 3 do presente estudo).

Tabela 3: Frequência de amostras de leite cru e cru refrigerado aceitável de acordo com padrões de mesófilos (CBT) estabelecidos pela IN. 51 e IN. 62, de unidades agrícolas familiares produtoras de leite no norte de Minas Gerais

\begin{tabular}{|c|c|c|c|c|c|c|c|}
\hline & & \multicolumn{3}{|c|}{ Leite cru \% } & \multicolumn{3}{|c|}{ Leite cru refrigerado $\%$} \\
\hline \multicolumn{2}{|c|}{ Época } & Limite $1^{*}$ & Limite $2^{*}$ & Limite $3^{*}$ & Limite $1^{*}$ & Limite $2^{*}$ & Limite $3^{*}$ \\
\hline Chuva & Aceitável & 20,0 & 12,0 & 12,0 & 14,0 & 9,0 & 9,0 \\
\hline Seca & Aceitável & 12,0 & 7,0 & 6,0 & 20,0 & 17,0 & 17,0 \\
\hline
\end{tabular}

Nota*: limite 1= CBT inferior ou igual a $7,5 \times 10^{4}$ UFC. $\mathrm{mL}^{-1}$; limite $2=\mathrm{CBT}$ inferior ou igual $4 \times 10^{5} \mathrm{UFC}$ $\mathrm{mL}^{-1}$; limite $3=$ Inferior ou igual a $3 \times 10^{5}$ UFC. $\mathrm{mL}^{-1}$.

$\mathrm{Na}$ época de chuvas a lama pode se acumular nos currais e salas de ordenha, as tetas dos animais ficam mais propensas a apresentarem sujidades, podendo assim contribuir para uma contaminação inicial do leite. A literatura descreve dados semelhantes quanto à maior contaminação do leite em épocas de chuvas. Lacerda et al.(2010) encontraram diferenças estatísticas em relação as médias de CBT e à época do ano, com maiores contagens de CBT no verão. No entanto, Roma Junior et al. (2009) encontraram maiores valores de CBT na primavera e menores resultados no outono e inverno.
A grande percentagem de amostras fora dos padrões ecidos pelas legislações encontradas na época seca, utilizado nestas propriedades. Mas conforme Nero et al.(2005), conservação destes, existem reflexos sobre sua qualidade, principalmente na redução de micro-organismo mesófilos.

O motivo da alta frequência de amostras inaceitáveis perante a IN.62, pode ser indicativo da falta de preparo dos produtores para atender as regulamentações previstas, pois o valor limite de CBT seria de $7,5 \times 10^{4}$ UFC. $\mathrm{mL}^{-1} \mathrm{em}$ julho de 2011, porém pela falta de adequação a este, alteraram-se o mesmo para $4 \times 10^{5} \mathrm{UFC} \cdot \mathrm{mL}^{-1} \mathrm{e}$ atualmente esta sendo exigido $3 \times 10^{4}$ UFC. $\mathrm{mL}^{-1}$ nas regiões sul, sudeste e centro-oeste (BRASIL, 2011) ou mesmo de incentivo por parte dos laticinios da região de estudo que não remuneravam os produtores pela qualidade do leite.

$\mathrm{Na}$ Tabela 4 estão sendo demonstradas as frequências de adequações das amostras de leite cru e cru refrigerado, por micro-organismos psicotróficos, coliformes a $45^{\circ} \mathrm{C}$ (somente leite cru) e Enterococcus spp.

Verificou-se a maior parte das amostras de leite dentro do valores estabelecidos pela legislação (BRASIL, 2011). Os valores desse estudo (Tabela 4) mostraram-se divergentes aos diagnosticados por Ataíde et al. (2008),que encontraram coliformes a $45^{\circ} \mathrm{C}$ e Escherichia coli, respectivamente em $78,6 \%$ e $42,9 \%$ de amostras de leite cru no estado da Paraíba. Citadin et al. (2009) verificaram em $58,06 \%$ das amostras de leite cru analisadas no Paraná a presença de coliformes com valor máximo de 1,1×104 UFC.mL $\mathrm{mL}^{-1}$. Okura e Ávila (2004) analisaram leite cru de microrregiões do Triângulo Mineiro e identificaram 21,40\% de Eschericha coli em aproximadamente 70 cepas suspeitas. Maciel et al. (2008) avaliaram 30 amostras de leite cru obtidas em três pontos de venda no município de Itapetinga e verificaram que todas as amostras estavam contaminadas com coliformes a $45^{\circ} \mathrm{C}$ em valores que variaram de $1,5 \times 10^{3}$ a $9,3 \times 10^{4}$ NMP.mL ${ }^{-1}$, respectivamente. Tebaldi et al. (2008) verificaram que $31,25 \%$ das amostras avaliadas apresentaram contagem de coliformes a $45^{\circ} \mathrm{C}$ acima de $10^{3} \mathrm{NMP} . \mathrm{mL}^{-1}$.

As fontes mais comuns de contaminação por esse grupo de bactérias são fezes (de origem humana e animal), funcionários, água e containers, ou seja, o manejo higiênico de ordenha e lavagem e desinfecção de utensílios e equipamentos são também fundamentais para evitar a contaminação do leite por coliformes. Como citado anteriormente para os altos níveis de 
Tabela 4: Frequência de amostras de leite cru e cru refrigerado em limites aceitáveis estabelecidos neste trabalho para psicrotróficos, coliformes à $45^{\circ} \mathrm{C}$ (somente leite cru) e Enterococcusspp , de unidades agrícolas familiares produtoras de leite no norte de Minas Gerais

\begin{tabular}{|c|c|c|c|c|}
\hline Micro-organismos & Época & & $\begin{array}{l}\text { Leite cru } \\
\%\end{array}$ & $\begin{array}{c}\text { Leite cru } \\
\text { refrigerado \% }\end{array}$ \\
\hline \multirow{2}{*}{$\begin{array}{l}\text { Psicrotróficos } \\
\left(\text { UFC. } \mathrm{mL}^{-1}\right)\end{array}$} & Chuva & Leite cru & 70 & 67 \\
\hline & Seca & Leite cru refrigerado & 52 & 67 \\
\hline \multirow{2}{*}{$\begin{array}{l}\text { Coliformes à } 45^{\circ} \mathrm{C} \\
\left(\mathrm{NMP}_{\mathrm{ml}} \mathrm{m}^{-1}\right)\end{array}$} & Chuva & Aceitável & 95 & ----- \\
\hline & Seca & Aceitável & 32 & ----- \\
\hline \multirow{2}{*}{$\begin{array}{l}\text { Enterococcus spp. } \\
\quad\left(\text { UFC. } \mathrm{mL}^{-1}\right)\end{array}$} & Chuva & Aceitável & 75 & 25 \\
\hline & Seca & Aceitável & 50 & 37 \\
\hline
\end{tabular}

Nota: Classes aceitáveis estabelecidas conforme descrito na metodologia.

aeróbios mesófilos, práticas inadequadas de higiene do ambiente podem ter interferido também na presença de coliformes a $45^{\circ} \mathrm{C}$.

Lacerda et al. (2010) afirmaram que o controle da qualidade da água também é fator fundamental para se prevenir a contaminação por coliformes, uma vez que é utilizada em todo processo produtivo.

Quanto à contaminação por Enterococcusspp, aépocainfluenciou apenas na contagem no leite cru refrigerado (Tabela 2), onde maiores médias foram obtidas na época chuvosa (época 1). A presença de Enterococcusspp. indica problemas nas condições higiênico-sanitárias de obtenção de leite (TEBALDI et al., 2008). Nessa época é comum acúmulo de lama e fezes nos currais e salas de ordenha, ao qual se deve a inexistência de práticas como retiradas de fezes e antissepsias do ambiente de ordenha, nas propriedades estudadas, podendo ter contribuído com esse aumento, pois estes micro-organismos são geralmente de origens ambiental e se desenvolvem também em temperaturas altas, características que são marcantes nessa época do ano na região em estudo, além de que, essas bactérias são usadas como indicadores da presença de material fecal nos alimentos, já que não se multiplicam no ambiente e são abundantes nas fezes animais.

Os níveis mais altos de contagem de Enterococcusspp. presentes no leite cru refrigerado (Tabela 2 ), pode estar associada às maiores médias microbianas encontradas no leite na época de seca, pois ao se refrigerar o leite pode ter favorecido o desenvolvimento desses micro-organismos, podendo ser resistentes até congelamento (IZIDRO et al., 2013;FREITAS, 2011; TEBALDI et al., 2008).

Enterococcus spp. é comumente encontrado na microbiota do leite cru, porém no país não são estabelecidos padrões de quantificação para o produto. Holm et al. (2004) encontraram valores de $5 \times 10^{3}$ UFC. $\mathrm{mL}^{-1}$ isolados de tanques de refrigeração na Dinamarca. TEBALDI et al. (2008) em isolamento de microorganismos no leite cru, identificaram propriedades leiteiras com contagens de até $1,4 \times 10^{7}$ UFC. $\mathrm{ml}^{-1}$ de micro-organismos Enterococcus spp., Freitas (2011) também encontraram cepas desses micro-organismos em amostras de soro do leite. Os estudos citados demonstram que houve casos da presença de micro-organismo em amostras de leite, bem como no presente estudo, onde em todas as propriedades foi encontrado cepas desses micro-organismos.
A Tabela 5 representa a frequência de amostras em limites recomendados para aeróbios mesófilos presentes em utensílios utilizados na produção do leite.

Quanto a higienização dos latões e baldes utilizados na ordenha, observaram-se (Tabela $5)$ apenas $1(0,83 \%)$ amostra dentro dos padrões recomendados neste estudo e $119(99,16 \%)$ amostras com altos níveis de contaminação de micro-organismos aeróbios mesófilos nos equipamentos de ordenha, o que indica deficiência na higienização dos mesmos. Avaliando os dados de contaminação de utensílios e os referentes à contagem de aeróbios mesófilos no leite, pode se inferir que estes dois possam estarrelacionados. Vários autores relatam que há redução significativa da CBT quando se realiza técnicas higiênicas sanitárias adequadas durante a etapa de produção, pois os equipamentos de ordenha constituem fontes de contaminação para o leite, assim como deficiências nos processos de higienização (GUERREIRO et al., 2005). Santana et al. (2004) afirmaram que os latões, tanques deexpansão, tetos mal higienizados e água residual dos equipamentos e utensílios de ordenha são os principais pontos de contaminação do leite na cadeia de produção.

Tabela 5: Frequência de contaminação por micro-organismos aeróbios mesofilos, de swabsde superfícies de baldes e latões, utilizados na ordenha em unidades agrícolas familiares produtoras de leite no norte de Minas Gerais

\begin{tabular}{c|c|c}
\hline Limites & Época chuvosa (\%) & Época da seca (\%) \\
\hline Aceitável & 0 & 0,83 \\
Inaceitável & 100 & 99,16 \\
\hline
\end{tabular}

Nota: aceitávelcorresponde a amostras que apresentaram UFC. $\mathrm{cm}^{2}$ menor ou igual 100 e fora amostras com UFC.cm² maior que 100, conforme APHA (2001)

Nunes et al. (2011) ao avaliarem o nível de contaminação de equipamentos utilizados na produção do em laticínios da região de Rio Pomba, no estado de Minas Gerais, observaram que condições inadequadas de higiene em ambientes contribuem para a contaminação cruzada dos produtos, reduz a vida de prateleira e aumenta o riscos de infecções alimentares, recomendando adoções de medidas de implantação de boas práticas de fabricação.

Arcuri et al. (2006) observaram associação entre a CBT e aplicação de produtos de limpeza nos equipamentos de ordenha e armazenamento do leite. Sendo os resultados da contagem padrão de até $1 \times 10^{5}$ UFC. $\mathrm{mL}^{-1}$ associados com procedimentos adequados de higienização dos equipamentos e do tanque de estocagem do leite, com todos os produtos de limpeza recomendados, tais como detergentes alcalinos e ácidos e sanitizantes.

Os níveis consideráveis de contaminação microbiana presentes nas amostras de leite podem estar relacionados diretamente com as práticas inadequadas de manejo e higienização 
que foram observadas nas propriedades estudadas. Estes dados tornam evidentes que capacitações, treinamentos e conscientizações dos produtores quanto à adoção de boas práticas de produção podem reduzir em valores consideráveis os níveis de contaminação. Relatos da literatura mostram que o grande sucesso na melhoria da qualidade do leite após capacitação, treinamentos e conscientização dos produtores e trabalhadores envolvidos na cadeia do leite (MATSUBARA, 2011; YAMAZI et al. 2010).

\section{Agradecimentos}

À FAPEMIG, CAPES, MEC/ProEXT, UFMG/PRPq, UFMG/PBEXT.

\section{Referências}

AMERICAN PUBLIC HEALTH ASSOCIATION. Compendium of methods for the microbiological examination of foods. 4th ed. Washington: APHA, 2001. 676 p.

ARCURI, E.F.; SILVA, P.D.L.; BRITO, M.A.V.P.; BRITO, J.R.F.; LANGER, C.C.; MAGALHÃES, M.M. Contagem, isolamento e caracterização de bactérias psicotróficas contaminantes de leite cru refrigerado.Ciência Rural, Santa Maria, v. 38, n. 8, p. 22502255, 2008.

ATAÍDE, W.S.; MACIEL, J.F.; LIMA, P.L.A.; LIMA, A.R.C.; SILVA, F.V.G.; SILVA, J.A. Avaliação microbiológica e físico-química durante o processamento do leite pasteurizado. Revista do Instituto Adolfo Lutz, v.67, n.1, p.73-77, 2008.

BRASIL. Instrução Normativa n. 51, de 20 de setembro de 2002. Aprova os regulamentos técnicos de produção, identidade e qualidade do leite dispõe sobre o Regulamento Técnico de Produção, Identidade e Qualidade de Leite Tipo A, B e C. Disponível em <http://extranet.agricultura.gov.br/sislegis-> Acesso em 12 de fevereiro de 2014.

BRASIL. Instrução Normativa n. 62, de 29 de dezembro de 2011. Altera o caput, exclui o parágrafo único e insere os $\S \S$ $1^{\circ}$ ao $3^{\circ}$, todos do art. $1^{\circ}$, da Instrução Normativa MAPA n ${ }^{\circ}$ 51 , de 18 de setembro de 2002, que passam a vigorar com a seguinte redação: Aprovar o Regulamento Técnico de Produção, Identidade e Qualidade do Leite tipo A, o Regulamento Técnico de Identidade e Qualidade de Leite Cru Refrigerado, o Regulamento Técnico de Identidade e Qualidade de Leite Pasteurizado e o Regulamento Técnico da Coleta de Leite Cru Refrigerado e seu Transporte a Granel, em conformidade com os Anexos desta Instrução Normativa. Brasília: [Senado Federal], 2012. Disponível em: <www.sindilat.com.br/gomanager/arquivos/ IN62_2011(2).pdf>. Acesso em: 10 set. 2012.

CITADIN, A.S.; POZZA, M.S. dos S.; POZZA, P.; NUNES, R.V.; BORSATTI, L.; MANGONI, J. Qualidade microbiológica de leite cru refrigerado e fatores associados: microbiological quality of raw milk and factors that influence its quality. Revista Brasileira de Saúde e Produção Animal, [S.I.], v. 10, n. 1, p. 52-59, jan./mar. 2009.

FREITAS, W.C. Aspectos higiênico-sanitárias, físico-químicos e microbiota lática de leite cru, queijo de coalho e soro de leite produzidos no Estado da Paraíba. 2011. Doutorado (Tese em Ciência e Tecnologia de Alimentos) - Centro de Tecnologia, Universidade Federal da Paraíba, João Pessoa, 2011.

GUERREIRO, K.; MACHADO, M.R.F.; BRAGA, G.C.B.; GASPARINO, E.; FRANZENER, A. da S.M. Qualidade microbiológica de leite em função de técnicas profiláticas no manejo de produção.Ciência Agrotécnica, Lavras, v. 29, n. 1, p. 216-222, Jan./Fev. 2005. Disponível em: <http://www.scielo.br/ pdf/cagro/v29n1/a27.pdf>. Acessoem: 12 marc. 2012.

\section{Conclusão}

Com o levantamento da contagem de micro-organismos presentes no leite e nos equipamentos de ordenha, das propriedades estudadas, diagnosticou-se contaminações que podem comprometer a qualidade higiênico sanitária do produto, uma vez que a maior frequência das amostras do leite analisadas não se enquadraram nos limites estabelecidos pelas legislações vigentes na época de estudo e nos limites atuais.
HOLM C, JEPSEN L, LARSEN M, JESPERSEN L. Predominant microflora of downgraded

danish bulk tank milk. Journal of Dairy Science, v.87, p.11511157, 2004

IZIDORO, T. B.;, PEREIRA, J. G.; SOARES, V. M.; et al.. Atividade proteolítica de bactérias psicrotróficas em leites estocados em diferentes temperaturas. Rev. Ceres, Viçosa, v. 60, n. 4, Aug. 2013 . Disponível em <http://www.scielo.br/scielo. php?script=sci_arttext\&pid=S0034-737X2013000400002\&lng=en \&nrm=iso>. Acesso em 25 Fev. 2014.

JAYARAO, Bhushan M.; WOLFGANG, David R. Bulk-tank milk analysis: A useful tool for improving milk quality and herd udder health. Veterinary clinics of North America: food animal practice, v. 19, n. 1, p. 75-92, 2003.

LACERDA L.M.; MOTA, R.A.; SENA, M.J. de. Contagem de células somáticas, composição e contagem bacteriana total do leite de propriedades leiteiras nos municípios de Miranda do Norte, Itapecuru-Mirim e Santa Rita, Maranhão. Arquivo do Instituto de Biologia, São Paulo, v. 77, n. 2, p. 209-215, 2010. Disponível em: <http://200.144.6.109/docs/arq/v77_2/lacerda. pdf>. Acesso em: 15 jan. 2012.

LANGONI, H.; PENACHIO, D.S.; CITADELLA, C.C.; LAURINO, F.; FACCIOLI-MARTINS, P.Y.; LUCHEIS, S.B.; MENOZZI, B.D.; SILVA, A.V. Aspectos microbiológicos e de qualidade do leite bovino. Pesquisa Veterinária Brasileira,Seropédica (RJ), v. 31, n. 12, p. 1059-1065, 2009.

MACIEL, J.F.; CARVALHO, E.A.; SANTOS, L.S.; ARAUJO, J.B.; NUNES, V.S. Qualidade microbiológica do leite cru comercializado em Itapetinga. Revista Brasileira de Saúde e Produção Animal, v.9, n.3, p.443-448, 2008

MATSUBARA, M.T. Boas práticas de ordenha para redução da contaminação microbiológica do leite no agreste pernambucano, Seminário Ciências Agrárias, Londrina, v. 32, n. 1, p. 277-286, jan./mar. 2011.

NERO, L.A.; MATTOS, M.R. de; BELOTI, V.; BARROS, M. de A.F.; PINTO, J.P. de A.N.; ANDRADE, N.J. de; SILVA, W.P. da; FRANCO, B.D.G.M.. Leite cru de quatro regiões leiteiras brasileiras: perspectivas de atendimento dos requisitos microbiológicos estabelecidos pela Instrução Normativa 51. Ciência e Tecnologia de Alimentos, Campinas, v. 2, p. $191-$ 195, 2005.

NERO, L.A.; MATTOS, M.R. de; BELOTI, V.; BARROS, M.A.F.; PONTES NETTO, D.; PINTO, J.P.A.N.; ANDRADE, N.J de; SILVA, W.P.; FRANCO, B.D.G. M. Hazards in nonpasteurizedmilkonretailsale in Brazil: prevalenceofSalmonella spp., Listeriamonocytogenesandchemicalresidues. BrazilianJournalofMicrobiology, [S.I.], v. 35, n. 3, p. 211-215, 2004. 
NUNES, N.B.S; CAHAVES; K.F., GRAVINA, C.S., MENDES, A.C.G.; MARTINS, A.D.O.; MARTINS, M.L. Avaliação Microbiológica de Equipamentos e Utensílios Utilizados em Laticínios da Região de Rio Pomba - MG. Revista Instituto Laticínios "Cândido Tostes",[S.I.], Juiz de Fora (MG), v. 66, p. 5378, 2011.

OKURA, M.H.; RIGOBELO, E.C.; ÁVILA, F.A. Isolamento e identificação de patógenos em leite cru produzido nas microrregiões do Triângulo Mineiro, MG. Ars Veterinária, Jaboticabal, SP, v. 21, n. 3, p. 324 - 331, 2004.

PINTO, C.L.O.; MARTINS, M.L.; VANETTI, M.C.D. Qualidade microbiológica de leite cru refrigerado e isolamento de bactérias psicrotróficas proteolíticas. Ciência e Tecnologia de Alimentos, Campinas, v. 26, n. 3, p. 645-651, Jul./Set. 2006. Disponível em: <http://www.scielo.br/pdf/cta/v26n3/31769.pdf>. Acesso em: 12 jan. 2012.

ROCHA, J.S.; BURITI, F.C.A.; SAAD, S.M.I. Condições de processamento e comercialização de queijo-de-minas frescal. Arquivo Brasileiro de Medicina Veterinária e Zootecnia, v. 58, n. 2, p. 263-272, 2006.

ROMA JUNIOR, L.C.; MONTOYA, J.F.G; MARTINS, T.T.; CASSOLI, L.D.; MACHADO, P.F. Sazonalidade do teor de proteína e outros componentes do leite e sua relação com programa de pagamento por qualidade. Arq. Bras. Med. Vet. Zootec., Belo Horizonte, v. 61, n. 6. 2009. Disponível em: <http://www.scielo.br/scielo.php?script=sci_arttext\&pid=S0102093 52009000600022\&lng=en\&nrm=iso>. Acessoem: 25 Jul. 2013.

SANTANA, E.H.W.; BELOTI, V.; MÜLLER, E.E.; BARROS, M.A.F.; MORAES, L.B.; GUSMÃO, V.V.; PEREIRA, M.S.

Milk contamination in different points of the dairy process. II

- PsychrotrophicsandProteolyticsmicroorganisms. Seminário

Ciências Agrárias, Londrina, v. 25, n. 4, p. 349-358, out. 2004.
SANTOS, M.V.; FONSECA, L.F.L. Estratégias para controle de mastite e melhoria da qualidade do leite. Barueri: Manole, 2007.

SARAN NETTO, A.; FERNANDES, R.H.R.; AZZI, R.; LIMA, Y.V.R. Estudo comparativo da qualidade do leite em ordenha manual e mecânica. Revista Instituto de Ciências da Saúde, [S.I.], v. 27, n. 4, 2009.

SAS. Statistical Analysis System Institute. 4.ed. Cary: SAS/STAT, 1997. 842 p.

SØRHAUG, T.; STEPANIAK, L. Psychrotrophs and their enzymes in milk and dairy products: quality aspects. Trends in Food Science \& Technology, v. 8, n. 2, p. 35-41, 1997.

TEBALDI, V.M.R.; OLIVEIRA, T.L.C. de; BOARI, C.A.; PICCOLI, R.H. Isolamento de coliformes, estafilococos e enterococos de leite cru provenientes de tanques de refrigeração por expansão comunitários: identificação, ação lipolítica e proteolítica. Revista Ciência e Tecnologia de Alimentos, Campinas, v. 28, p. 753760, 2008. Disponível em: <http://www.scielo.br/pdf/cta/v28n3/ a36v28n3.pdf>. Acesso em: 18 fev. 2012.

VALLIN, V.M.; BELOTI, V.; BATTAGLINI, A.P.P.; TAMANINI, R.; ANGELA, H.L. da; SILVA, L. C.C da. Melhoria da qualidade do leite a partir da implantação de boas práticas de higiene na ordenha em 19 municípios da região central do Paraná. Seminário Ciências Agrárias, Londrina (PR), v. 30, n. 1, p. 181188, 2009. Disponível em: <http://www.uel.br/revistas/uel/index. php/semagrarias/article/viewArticle/266>. Acesso em: 14 marc. 2012.

YAMAZI, A.K.; MENDONÇA. P.; VIÇOSA, G.N.; ORTOLANI, M.B.T.; NERO, L. A. Práticas de produção aplicadas no controle de contaminação microbiana na produção de leite cru, BioscienceJournal, Uberlândia, v. 26, n. 4, p. 610-618, 2010. 